\title{
Analysis on the Connotation and Necessity of College Students' Leadership Education
}

\author{
Du Bin ${ }^{1}$, Luo Xiaoyun ${ }^{2}$, Yu Tingrong ${ }^{2}$ \\ ${ }^{1}$ College of Coutinuing Education and Vocational Education, Yunnan Agrictural University, Yunnan 650201, \\ China \\ ${ }^{2}$ Department of Student affairs, Yunnan Agrictural University, Yunnan 650201, China
}

Keywords: college students; leadership education; connotation; necessity; analysis and research

\begin{abstract}
With the development of the times and social progress, the education of college students in our country is not only embodied in knowledge, but also for the ability of college students. The leadership education of college students is the latest requirement of university education in the era of market economy. The training of leadership ability of Chinese universities can provide some high quality talents for the new social environment to a certain extent. At present, it is of great significance to improve the education knowledge and comprehensive quality ability of college students and to cultivate the ability of leadership. This article first expounds the connotation of College Students' leadership education at the present stage, and then analyzes the necessity of training college students' leadership education, and then puts forward corresponding measures.
\end{abstract}

\section{Introduction}

At present, when our colleges and universities are educating college students' leadership, they usually carry out some practical education on the basis of past education, according to our realistic educational situation, historical and cultural background, and the establishment of future education and training goals. Most effective leadership education will learn from the advanced technology and theory of western developed countries, and cultivate and educate college students' leadership better, and put forward effective countermeasures and policies [1].

\section{The connotation of College Students' leadership education}

In most cases, colleges and universities will be understood as an education for student management in the leadership education of students. Because leadership education is different from other education, it has certain situational and complexity, and most of the future leadership of college students will be applied to work with government and enterprises. Few schools will limit the study of college leadership to the masses of the people. Therefore, there are many viewpoints and Research on leadership ability education. Generally speaking, leadership is mainly about the ability of a unit or organization leader to effectively change other people's behavior and achieve their goals under certain circumstances. Secondly, some researchers think leadership mainly refers to the pursuit of goals in the process of leadership. Thirdly, researchers believe that leadership is actually a dynamic process, mainly through the joint efforts of leaders and leaders. The main concern is leaders' influence on leaders [2]

I believe that leadership should not only be the strength of leaders, but also the ability of leaders and others. Some within the unit, can be flexible, have the predictive power for future development of the situation of enterprises, for some uncertain things to try to tolerate coordination, and should also have a communication and coordination ability and the team's ability to maintain etc. The stage of China's university students should possess personal goals and team goals in a timely manner to my reflection and self management, can have the ability to handle complex matters, in fact, pay more attention to the autonomy of the students, this is the core content of College Students' leadership [3]

At this stage, the basic elements of the leadership ability of college students are mainly divided 
into the following aspects. First of all, values are an important part of College Students' ability to lead. With the development of society, people's vision and values will gradually change with the trend of the atmosphere. Under the influence of the great environment, Chinese college students will gradually change their values. Therefore, through the cultivation of students' leadership, to a certain extent, improve college students identify and adapt to the ability to control the affairs and, full of social political responsibility and self realization for the purpose of research, better realize their own leadership ability and values education enhancement. Secondly, the consciousness of leadership is an important prerequisite for the cultivation of leadership. Marx's doctrine emphasizes that consciousness has a dynamic role, which is the understanding and reaction of the people to the objective world. In China's traditional culture, many adherence thoughts have certain limitations, and lack of persistence and risk spirit seriously lead to the lack of leadership consciousness of many college students. In the current stage of leadership education for college students, leadership awareness has become the prerequisite and foundation for the smooth progress of College Students' leadership education. Again, the leadership charm is the key content of the college students' leadership education. Whether a person has leadership in a job or life is usually related to the knowledge and intellectual ability of the leader. Finally, leadership and leadership education are closely linked. The leadership art of college students mainly refers to the leadership of a unit should show certain characteristics and behaviors in leadership style, match leaders' personal characteristics and situations, so that we can fully improve leadership effectiveness. Therefore, our higher education system for college students should be good leadership theory and practice education, to a certain extent, the social culture and shaping a more excellent leadership personnel, capable of self management and team building within the unit, in the face of problems when calm treatment, with good communication skills and resourceful. To appeal and appeal [4]

\section{The necessity of College Students' leadership education}

Chinese college students have some special characteristics when they carry out leadership education in Colleges and universities. Leadership education for college students differs from other students in other education, which is aimed at college students who have no position or position. Because college students are in a certain degree of lack of real duties and rights, so the lack of the master and display platform. Therefore, in the leadership education of college students, we should focus on the analysis of the leadership knowledge and the relationship between ability and quality. Second, the college students' leadership education space is more open. In the course of education, students can also consider learning outside the classroom, and the campus network, because the professor in the classroom or the majority of theoretical knowledge and practice of extra-curricular activities, show the rich and colorful forms of learning, and the rapid development of Internet era, information dissemination and reception has a high timeliness. To a certain degree of leadership education for college students. Third, the leadership education of college students has a diversified trend. The so-called leadership education is not only the theoretical knowledge that teachers teach to students, but also the knowledge and ability of life, and the cultural atmosphere from friends and family members. These are the important means for college students to learn in the practice experience. In life, you can learn leadership related knowledge and ability to improve quality and values to a certain extent. According to the object of educational leadership, we can effectively use the values to conduct comprehensive and effective analysis, open the educational space better, learn more effective educational means, and adopt a more effective development mode to carry out leadership education for college students [5].

Our college is a social group that the most potential, so in students' leadership education, is not only the efforts for the development of the present college students, on the other hand or on higher education to improve, to better meet the needs of talents in social development. Therefore, the leadership education of college students should be paid much attention by all walks of life. In view of the necessity of College Students' leadership education at the present stage, it can be considered from the following aspects [6].

College Students' learning in higher education should not only learn knowledge, but also should 
learn the comprehensive quality of the basic ability, behavior development and psychological development of unified learning, and learning and life experiences with increased year increase, will increase the inner sense of social responsibility and moral art to a certain extent, to improve college students' leadership is of great help. For the future college students to deal with the ability to deal with affairs, and the ability to express, innovation, job hunting ability can be constantly enriched and improved. Second, it is the responsibility of colleges and universities to carry out leadership education for college students. College students are the future and national hope of the motherland. The quality of their leadership is directly related to the future development and economic development of the country. Therefore, colleges and universities should take the initiative to cultivate their leadership and take better responsibility for training. In the leadership education of students, colleges and universities must make clear the goal of education and the main body of education, and the high efficiency of the whole social learning resources and educational resources. Third, leadership education for college students is necessary in the process of social development. In the current stage of development and progress, knowledge culture has become a part of the social development of an important force. In the process of economic globalization and information development, the society needs the people with leadership to integrate and develop the social resources. By carrying out leadership education for college students, colleges and universities strive to cultivate students' lofty ideals and beliefs for serving the society, and establish leaders who can serve the future society.

The importance of student leadership education has proved that the development of China's current policy, some just graduated from college of large village village learning, which requires students to have the leadership, to a certain extent to the college student leadership education and leadership resources development has important significance. Leadership education for college students is of great significance to China's economic globalization. It can increase the soft power of our economic operation, improve our competitiveness in the world and promote our country to build a strong and democratic socialist modern country. In addition, the effective development of our country college student leadership education, on the one hand, China's social integration scattered on the educational resources, help to improve college students' Ideological and political education, on the other hand also has an overall increase of college students in the life and work of self management of comprehensive quality and ability of life.

\section{Strengthen the education measures of College Students' leadership}

First of all, China's higher schools should change their traditional educational ideas and try to add the leadership education to compulsory education. The task and responsibility of colleges and universities is to cultivate students' knowledge ability and comprehensive quality. At present, many schools in our country attach importance to knowledge imparting and skills training, but neglect the cultivation of students' personality and leadership, which has led to the failure to meet the needs of social development after graduation. The effective transformation of educational ideas and thinking is the focus of higher education at the present stage. Secondly, colleges and universities should choose professional teachers to train schools and establish a good leadership education curriculum model. Open leadership education has special and innovative characteristics of colleges and universities, so without thinking will encounter a lot of problems, so the university should hire professional teachers with the management of the establishment of the curriculum system, and combining the actual situation, create teachers in school related professional internal examination competition way through the selection of teachers. At the time of leadership education for students, schools should set up reasonable courses, hardware and software facilities to be in place. Let the students identify the problems and the characteristics of the related subjects, so that students can realize the advantages of leadership and the connotation of leadership. The need doctrine is that when setting up courses, we must base on relevant training programs, improve and supplement leadership knowledge better, and establish and improve the leadership curriculum system. Third, leadership education is not only theoretical education, but also should pay more attention to practice education. At the present stage of China's colleges and universities should be within the various 
schools can use the effective integration of resources, give full play to students within the school and other community organizations, let the students after learning of theoretical knowledge, to experience leadership, let the students in practice in a long. For example, in the school class management, we can achieve the form of rotation class cadres, so that every student in the class can feel leadership and let more students exercise in managing class affairs. For example, we can establish their own organizations in the school, organize and carry out a number of meaningful activities to improve the leadership of college students. It can also participate in volunteer activities and volunteer activities organized by the school, so that college students can strive to improve themselves, develop related communication skills and social skills, and solve unexpected problems. Students through school leadership education can get the true experience of the role of leaders, and the theoretical knowledge in the classroom can be understood and absorbed.

First, college students should study hard and cultivate their own consciousness of struggle. College students themselves should have some sense of social responsibility and ideals and beliefs. They should fully believe that their careers can be successful, and they can show persistence in their spirit and study hard. Our college students should establish a wide range of learning interests and good learning spirit. We should continue to explore and research new things, and have their own views and ideas. Something happens to be able to think independently, not others. In the case of difficulties, we should learn to adapt flexibly, find new ideas and solve ideas. Finally, we should be good at observing what happened around it, digging its essence, and solving it. Second, the management of college students has rich professional knowledge and practical knowledge. In this way, when a leader is in trouble, it can solve the problem quickly. And college students should also be involved in some management and management knowledge, which is of great importance to the promotion of leadership. Finally, we should also carry out the operation and accumulation in practice, and learn to do things independently. Third, college students should actively carry out social practice activities to cultivate leadership consciousness and leadership skills. As a leader, college students should establish a certain sense of leadership and summarize the experience of leadership. We should not focus only on the results, no matter the process, this is a wrong way. We should work hard on the ground, pay attention to the smile in practice, and gradually summarize it into profound knowledge.

\section{Conclusion}

To sum up, the leadership of college students plays a vital role in the future development and social needs of college students. But at the present stage, the development and research of Chinese college students' leadership education is still in a relatively primary level. Therefore, it is very important to understand the connotation and necessity of College Students' leadership education, which is very important for the self development of college students in China. This article analyses the connotation and necessity of College Students' leadership education successively, and finally expounds the measures to strengthen the education of College Students' leadership. It is believed that through this study, it can be helpful to the analysis and research of future college students' leadership education.

\section{References}

[1] Xie H J, Yao C H. The analysis on the basic connotation and necessity of life education for college students[J]. Journal of Jiamusi Education Institute, 2012.

[2] Cui Y J, Wang B X. College Students' Leadership: Treasure in the Ivory Tower[J]. Heilongjiang Researches on Higher Education, 2015

[3] Xiu-Juan L I, Marxism S O. Leadership Education for College Students Under the Perspective of Marx's Practice Viewpoint[J]. Journal of Bengbu University, 2016.

[4] Jing D. Research and Thinking of Shanghai College Students' Socially Responsible Leadership[J]. Contemporary Youth Research, 2013. 
[5] Cao H Y. The ideological and political education mechanism of college students[J]. Journal of Jiamusi Vocational Institute, 2017.

[6] Wang F. Students' Leadership Connotation and Developmental Strategies[J]. Research in Educational Development, 2012. 